\title{
Study on the Evolution Law of Fracture Field in Full-Mechanized Caving Mining of Double System and Extrathick Coal Seam
}

\author{
Feng Du, Wenqiang Wang, and Zhenhua Li iD \\ School of Energy Science and Engineering, Henan Polytechnic University, Jiaozuo 454000, Henan, China \\ Correspondence should be addressed to Zhenhua Li; jzlizhenh@163.com
}

Received 24 June 2020; Revised 22 September 2020; Accepted 28 September 2020; Published 9 October 2020

Academic Editor: Fengqiang Gong

Copyright (c) 2020 Feng Du et al. This is an open access article distributed under the Creative Commons Attribution License, which permits unrestricted use, distribution, and reproduction in any medium, provided the original work is properly cited.

\begin{abstract}
During the full-mechanized caving mining, the overburden strata in the double system and extrathick coal seam of the Datong mining area are largely damaged. Water and harmful gas in the old goaf may be discharged when overburden fractures evolve to the upper goaf, which poses a major threat to the normal production of the panel. To study the movement of overburden strata and the evolution of fracture field under the full-mechanized caving mining of the double system and extrathick coal seam, panel 8309 of Tongxin mine was taken as the research object; the evolution rule of fracture field in the full-mechanized caving mining of the double system and extrathick coal seam was obtained through field measurement and physical similar simulation. The results show the following: (1) the far-field and near-field key strata play a decisive role in controlling the fracture evolution of overburden strata. When the far-field key strata break and the development height of fractures reaches $220.9 \mathrm{~m}$, panel 8309 is connected with the overburden goaf. (2) Based on the "O-shape circle" theory of mining fracture, with the continuous advance of the panel, the overburden breaks periodically, and a "fracture surface" with a certain angle of $61^{\circ}-67^{\circ}$ can be formed along with the advancing direction of the panel. (3) When the key strata are broken and the development height of fractures reaches the maximum, the fracture surface is formed as the "main fracture surface," which is the only downward discharge pathway for goaf water and harmful gas. The overall shape fracture surface is "inverted trapezoid" in the upper part and "positive trapezoid" in the lower part. (4) Based on the field measurement of the water level of borehole and the observation of mine pressure, the correctness of the evolution law of the similar simulated fracture field is verified.
\end{abstract}

\section{Introduction}

Underground mining is widely applied to extract coal resources. With the gradual depletion of the upper coal resources, deep mining has been gradually developed $[1,2]$. During the deep mining of coal, a large amount of old goaf water and hazardous gas is accumulated in the overburden goaf $[3,4]$. With the continuous advance of the panel from the open-off cut, the overburden fracture continues to evolve upward $[5,6]$. If the caving space is large enough and the fracture develops from the bottom to the goaf, the old goaf water and harmful gas will be discharged, threatening the normal mining of the panel [7-9]. Therefore, it is necessary to study the law of fracture evolution of overburden strata.

The research shows that different mining fractures can be formed in the overburden strata and the goaf after mining under different geological conditions [10,11]. Academician Qian Minggao proposed the O-shape circle theory of mining fractures [12]. Xu et al. studied the influence of the location of the main key strata of the overburden on the height of the water-conducting fracture zone and the calculation method [13-16]. Considering the geological conditions of the Datong mining area, Bin et al. established the "triangle plate" structural mechanics model of the formation of the "horizontal O-X" fracture of far-field key strata [17-19]. Li et al. established a mathematical model for the dynamic evolution of the mining-induced fracture elliptic paraboloid zone considering the mining height and the spacing between the first key strata and the roof of the coal seam [20]. Wang et al. studied two different evolution states of structural stability changes of the main key strata under the influence of mining height and coal seam spacing [21]. Lin et al. proposed a 
simplified engineering model and its dynamic evolution process of "mining-induced fracture rounded rectangular ladder belt [22]." The above achievements have played a positive role in the practice of coal mine safety production and disaster prevention.

However, the above research studies are concentrated on the mining of thick coal seam and the coal seam with thickness below. At present, many scholars at home and abroad have studied the development law of overburden breakage characteristics and mining-induced fracture in overburden strata, and the mining thickness of coal seam is below $8 \mathrm{~m}[6,23,24]$. However, the average thickness of Carboniferous ultrathick coal seam in Datong mining area is $15 \mathrm{~m}$, and the damage area of the rock strata is usually enlarged with the highly developed mining fractures $[25,26]$. The water and harmful gas in the old goaf are discharged when overburden fractures evolve to the upper goaf. The research on the evolution process of mining overburden fracture in the mining of extrathick coal seam (coal seam thickness $>8 \mathrm{~m}$ ) has been rarely performed. Therefore, the study on the evolution law of fracture field in full-mechanized caving mining of the double system and extrathick coal seam should be carried out systematically.

Based on the fully mechanized panel 8309 in Tongxin mine, the relationship between far-field key strata, near-field key strata, and the evolution of overburden fracture is analyzed in this paper. The generation and evolution of the overburden fracture under the condition of superthick coal seam are explained. This study provides a theoretical basis for the study of the development of the overburden fracture and the treatment of the water and gas drainage in the overburden goaf.

\section{Engineering Geological Conditions}

Datong mining area is a mining area of double-system coal seam with the occurrence of Jurassic and Carboniferous coal seams. Jurassic coal seams have a wide occurrence with numerous layers. After mined for more than 100 years in Jurassic coal seams, a large number of mined-out areas are generated. At present, the main coal seam in the mining area is coal seams 3-5\# of the carboniferous system, with a thickness of $14-20 \mathrm{~m}$. The longwall mining with top coal caving was performed. After mining, the overburden collapsed and moved in a large space, with a wide range of influence. In Tongxin coal mine, coal seams $3-5 \#$ were the main coal seams.

In this paper, panel 8309 was taken as the research background. The coal seam thickness of the panel was $10.8-18.00 \mathrm{~m}$, the dip angle was $0^{\circ}-3^{\circ}$, the coal seam elevation was $818-842 \mathrm{~m}$, the ground elevation was $1294.3-1443 \mathrm{~m}$, the inclined length of the panel was $200 \mathrm{~m}$, and the strike length was $2843 \mathrm{~m}$. Panel 8309 was covered with 14\# coal seam goaf of the Jurassic system. A large amount of water and toxic and harmful gas was accumulated in the goaf, as shown in Figures 1 and 2.

\section{Field Observation Results of Water Level in Borehole}

To study the affected area of the overburden strata and the evolution law of the rock fracture during the mining process, a water level monitoring device was installed for borehole $1 \#$. Borehole $1 \#$ was located in the middle of the front of the panel, and the final depth of drilling was $592.1 \mathrm{~m}$. The initial water level monitoring probe was $57.62 \mathrm{~m}$ below the water surface. When the probe was pushed from the panel 8309 to $232.6 \mathrm{~m}$ away from borehole $1 \#$ and from the panel 8309 to $85.9 \mathrm{~m}$ away from borehole $1 \#$, the water level changes were recorded, as shown in Figure 3.

It can be seen from the above figure that the water level change of water level monitoring hole $1 \#$ can be roughly divided into three stages as follows:

(1) Slow decline stage: within $232.6-136.6 \mathrm{~m}$ from panel 8309 to water level monitoring hole $1 \#$, water level of the borehole slowly drops at the speed of $0.1-0.2 \mathrm{~m} / \mathrm{d}$.

(2) Slowly rising stage: within $132.1 \mathrm{~m}$ to $-5.5 \mathrm{~m}$ from the panel 8309 to the borehole, the water level of the borehole rises at a speed of $0.02-0.93 \mathrm{~m} / \mathrm{d}$.

(3) Sudden drop stage: within $-5.5 \mathrm{~m}-85.9 \mathrm{~m}$ through the borehole of panel 8309, the water level of the borehole drops rapidly. In the range of -5.5 to $-62.5 \mathrm{~m}$, the drilling water level drops at a speed of $1.5-4.2 \mathrm{~m} / \mathrm{d}$, and in the range of -62.5 to $-72.5 \mathrm{~m}$, the drilling water level drops at a speed of 18.48-25.7 m/ d. Mining activities result in the evolution of overburden fracture, and the change of borehole water level significantly affects the evolution of overburden fracture. Therefore, the similar simulation and the mine pressure observation were used to explore the evolution law of overburden fracture during the mining of extrathick coal seam.

\section{Similar Simulations of the Evolution Characteristics of Overburden Fracture Field}

\subsection{Experimental Design of the Physical Model}

4.1.1. Establishment of the Physical Model. The discrimination results were obtained by the location discrimination method of key strata of overburden [27, 28], and the definition of near-field and far-field key strata [29, 30], as shown in Table 1. The research basis for the physical similar simulation includes the geometric similarity, the kinematic similarity, and the dynamic similarity [31, 32]. According to similar conditions, physical and mechanical parameters of coal seam, and simulated height of overburden strata (see Tables 1 and 2), the material proportion of physical similar simulation was determined. The plane model was adopted, the model size was $2500 \mathrm{~mm} \times 1283 \mathrm{~mm} \times 200 \mathrm{~mm}$ (length $\times$ height $\times$ width), the geometric similarity ratio $\mathrm{CL}=1: 200$, the unit weight similarity ratio $C \gamma=1: 1.5$, and 


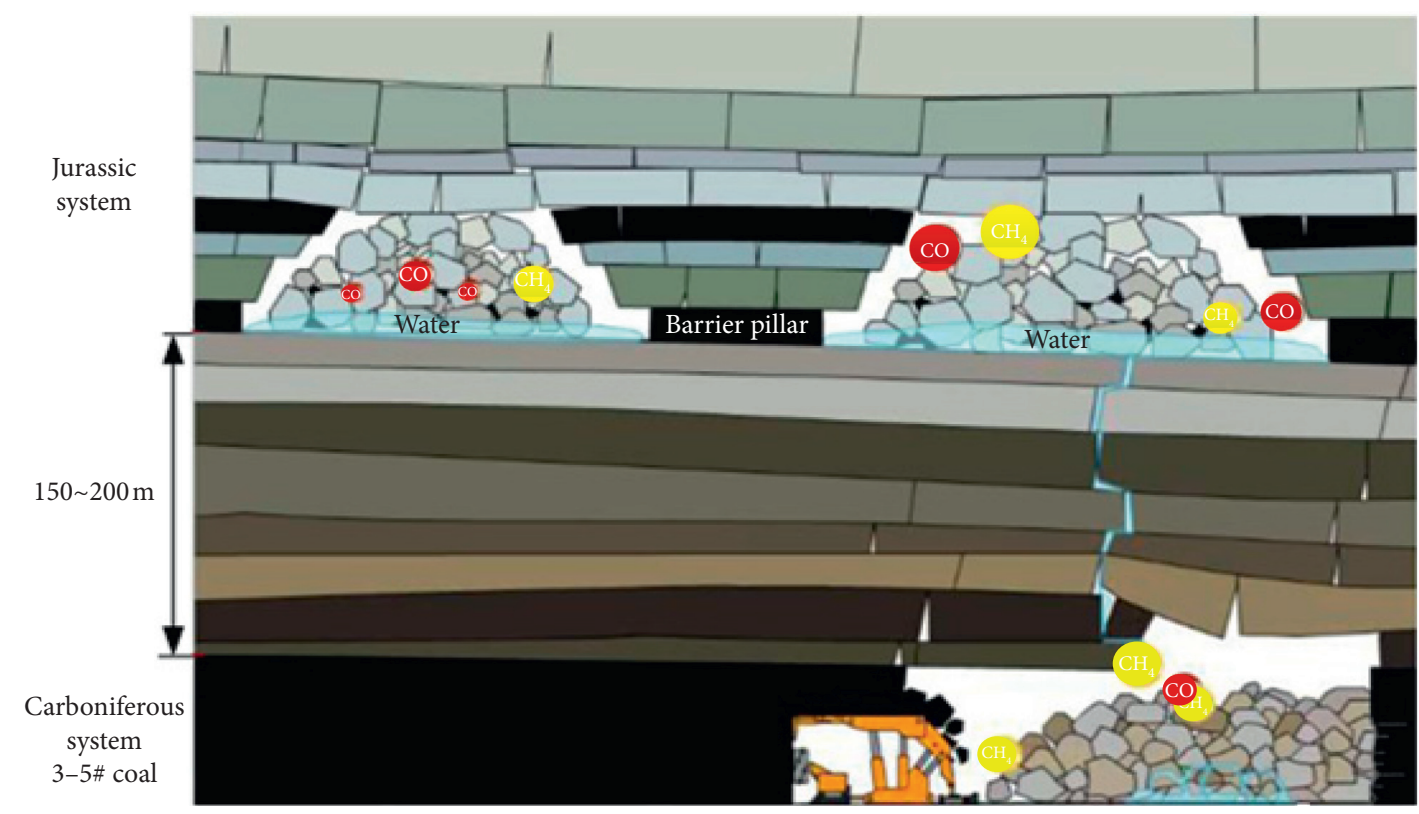

FIGURE 1: Schematic diagram of water and gas discharge disasters in double-seed mining in Datong mining area.

the similarity ratio of stress to strength $\mathrm{C} \sigma=1: 300$. Similar materials included river sand, cement, light calcium carbonate, gypsum, borax, and water. Mica powder was sprinkled on each layer of the laid rock to simulate the layer stratification. The unsimulated rock layer above the model was compensated by hydraulic cylinder loading. Referring to geological data, the buried depth of the top layer of the model was $340 \mathrm{~m}$, the average unit weight of the overburden strata was $2.4 \mathrm{t} / \mathrm{m}^{3}$, and the value of the upper boundary was 8.2 $\mathrm{MPa}$.

4.1.2. Excavation Steps in the Physical Model. The layout of measuring points and excavation part of the model is shown in Figure 4. The key strata refer to the strata which control the whole or partial overburden movement from the overburden to the surface. In this paper, the near-field key strata are the key strata close to the 8309 working face, which are the siltstone; while the far-field key strata are the key strata far from the 8309 working face, which are the coarse sandstone. After the model was naturally air-dried, the pressure above the rock strata was slowly increased from $0 \mathrm{MPa}$ to $0.1 \mathrm{MPa}$ by adjusting the control console. Then, the pressure was gradually increased to $0.18 \mathrm{MPa}$ and maintained at $0.18 \mathrm{MPa}$. Coal seam $14 \#$ was excavated $380 \mathrm{~m}$ from left to right, and then coal seams 3-5\# were excavated $380 \mathrm{~m}$ from left to right, and $20 \mathrm{~m}$ for each excavation.

\subsection{Overburden Movement and Fracture Evolution in Stope}

4.2.1. Overburden Fracture and Fracture Evolution Characteristics in Stope. The far- and near-field key strata were relatively thick with the large strength and good bearing capacity, and the soft strata were relatively small in thickness and low in strength. When 3-5\# extrathick coal seams were mined, the overburden fractured with the breakage of near- field key strata or far-field key strata. Therefore, the key stratum structure has a controlling effect on the whole stratum movement, and the fracture of near- and far-field key strata determines the movement and fracture evolution of the whole overburden.

According to the experimental results, the failure of overburden can be divided into two stages, near-field key stratum fracturing stage and far-field key stratum fracturing stage:

(1) Near-field key stratum fracturing stage: when the panel was advanced to $120 \mathrm{~m}$, the overburden fractured to the bottom of the near-field key strata, and there was a large separation area at the bottom; when the panel was advanced to $160 \mathrm{~m}$, the near-field key strata fractured, and a part of the upper strata also broke down. The overburden break did not develop to the bottom of the far-field key stratum 1 . The reasons are as follows: the space of the separation area is not enough, the overburden fracturing distance is not reached, and the overburden fracture does not develop upward.

(2) Far-field key stratum fracturing stage. When the panel was advanced to $180 \mathrm{~m}$, the overburden was fractured to the bottom of the far-field key strata, and the rock layer inside and above the far-field key strata was stable; when the panel was advanced to $240 \mathrm{~m}$, the far-field key stratum 1 was broken, the interlayer in the middle of the far-field key strata was fractured along with the far-field key stratum 1, and the bottom of the far-field key stratum 2 was separated from the layer. However, due to the lack of space in the separation zone, the far-field key stratum 2 did not break, with the continuous advance of the panel, when the panel advanced to $300 \mathrm{~m}$, the far-field key stratum 2 fractured, and overburden strata were 


\begin{tabular}{|c|c|c|c|c|c|c|}
\hline Stratum & Lithology & Columnar & No. & $\begin{array}{c}\text { Thickness } \\
(\mathrm{m})\end{array}$ & $\begin{array}{l}\text { Burial depth } \\
\text { (m) }\end{array}$ & Key strata location \\
\hline \multirow{31}{*}{ Jurassic } & Siltstone & $\therefore$ & 1 & 3.4 & 342.7 & \\
\hline & Fine-grained & $-\therefore-7$ & 2 & 6.4 & 346.1 & \\
\hline & Siltstone & & 3 & 8.2 & 354.3 & \\
\hline & Coale 14 & & 4 & 2.9 & 357.2 & \\
\hline & Siltstone & & 5 & 8.6 & 365.8 & \\
\hline & Sandy mudstone & E-"---- & 6 & 6.5 & 372.3 & \\
\hline & Medium-graine & सा" & 7 & 4.3 & 376.6 & \\
\hline & Mudstone & & 8 & 4.2 & 380.8 & \\
\hline & Coarse-grained & & 9 & 3.6 & 384.4 & \\
\hline & Medium-graine & & 10 & 3.4 & 387.8 & \\
\hline & Mudstone & & 11 & 9.1 & 396.9 & \\
\hline & Fine-grained & & 12 & 1.6 & 398.5 & \\
\hline & Mudstone & & 13 & 2.0 & 400.5 & \\
\hline & Fine-grained & & 14 & 4.3 & 404.8 & \\
\hline & Mudstone & & 15 & 17.3 & 422.1 & \\
\hline & Fine-grained & & 16 & 5.3 & 427.4 & \\
\hline & Siltstone & & 17 & 27.7 & 455.1 & \multirow{3}{*}{ Far-field key strata } \\
\hline & Fine-grained & & 18 & 2.6 & 457.7 & \\
\hline & Siltstone & & 19 & 11.7 & 469.4 & \\
\hline & Sandy mudstone & & 20 & 7.3 & 476.7 & \\
\hline & Fine-grained & & 21 & 3.0 & 479.7 & \\
\hline & Sandy mudstone & & 22 & 2.0 & 481.7 & \\
\hline & Coarse-grained & & 23 & 6.4 & 488.1 & \\
\hline & Coarse sandstone & & 24 & 4.6 & 492.7 & \\
\hline & Coarse-grained & & 25 & 3.2 & 495.9 & \\
\hline & Coarse sandstone & & 26 & 2.8 & 498.7 & \\
\hline & Coarse-grained & & 27 & 5.5 & 504.2 & \\
\hline & Coarse sandstone & & 28 & 12.7 & 516.9 & Near-field key strat \\
\hline & Coarse-grained & & 29 & 5.8 & 522.7 & \\
\hline & Coarse sandstone & & 30 & 7.0 & 529.7 & \\
\hline & Mudstone & & 31 & 5.2 & 534.9 & \\
\hline \multirow{11}{*}{ Permian } & Sandy mudstone & & 32 & 3.6 & 538.5 & \\
\hline & Coarse-grained & & 33 & 6.2 & 544.7 & \\
\hline & Sandy mudstone & & 34 & 4.1 & 548.8 & \\
\hline & Medium-graine & & 35 & 2.4 & 551.2 & \\
\hline & Coarse-grained & & 36 & 2.4 & 553.6 & \\
\hline & Sandy mudstone & & 37 & 5.9 & 559.5 & \\
\hline & Coarse-grained & $\cdots$ & 38 & 3.1 & 562.6 & \\
\hline & Mudstone & 26 & 39 & 6.7 & 569.3 & \\
\hline & Sandy mudstone & & 40 & 1.9 & 571.2 & \\
\hline & Coarse-grained & & 41 & 5.3 & 576.5 & \\
\hline & Sandy mudstone & & 42 & 1.6 & 578.1 & \\
\hline \multirow{2}{*}{ Carboniferous } & Coale 3-5 & & 43 & 14.0 & 592.1 & \\
\hline & Sandy mudstone & 望望 & 44 & 8.8 & 600.9 & \\
\hline
\end{tabular}

FIGURE 2: Drilling histogram of panel 8309.

subsequently bent and separated. The horizontal fracture developed directly to the goaf in coal seam 14\#. At this time, there were also small vertical fractures. The panel was connected with the 14\# coal seam goaf, but the opening of the upper part of the fracture face was very small. Therefore, only a small 


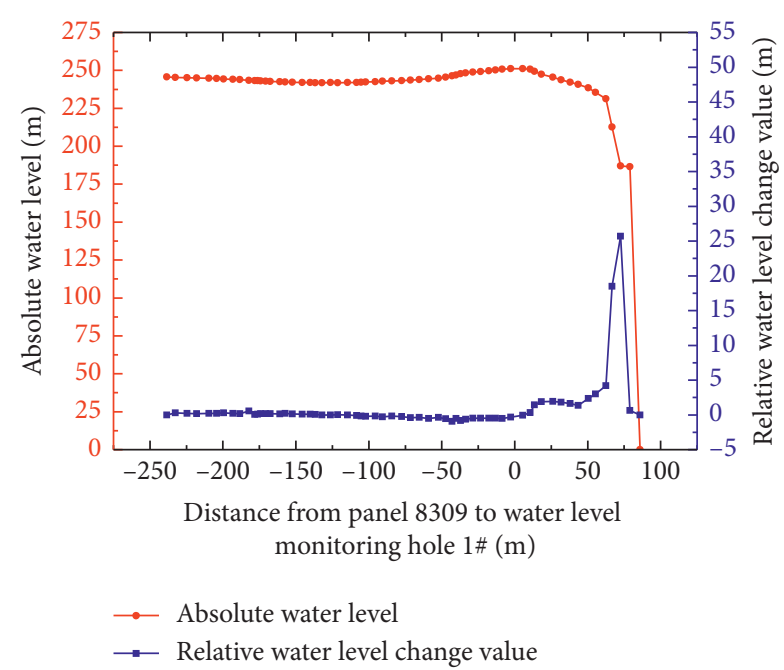

Figure 3: Variation of water level in drilling with the advance of the panel.

amount of water and gas can be discharged, which had a rare effect on the safety production of the work surface.

Based on the O-shape circle of mining fracture, with the continuous advance of the panel, the overburden strata fractured periodically, and a fracture surface with a certain angle was formed in the coal seam, which is called "the fracture surface." Afterwards, when the fracture surface developed to the overburden goaf, the water and harmful gas in the overburden goaf were discharged to the panel through the fracture surface, which is called "the main fracture surface." The main fracture surface was divided into three parts: the first part was from the coal seam roof to the bottom of the far-field key strata, with an angle of $62^{\circ}$; the second part was only the far-field key strata, with a large fracture angle, where the angle of the fracture surface here was greater than $62^{\circ}$; the third part was the goaf from the top of the far-field key strata to coal seam 14\#. The fracture developed in the right direction, and the overall shape was "inverted trapezoid" in the upper part and "normal trapezoid" in the lower part, as shown in Figures 5 and 6.

4.2.2. The Detailed Result of Five Survey Lines for Displacement. The vertical displacement curves of five survey lines are obtained in Figure 7. Specifically, the survey lines of number 2 and number 4 for displacement are located at the top of far-field key strata and near-field key strata, respectively. The characteristics of vertical displacement of key strata and the distribution of the size of broken block under different advanced distances are obtained, by analyzing the data of survey lines with the XITUDP system. When the advanced distance of working face changes from $140 \mathrm{~m}$ to $160 \mathrm{~m}$, the near-field key strata break initially, and the subsidence value at the top of near-field key strata is $3.5 \mathrm{~m}$; when the working face advances to $240 \mathrm{~m}$, the nearfield key strata periodically break, and the broken distance is $80 \mathrm{~m}$, which is shown in Figure $7(\mathrm{~d})$. When the working face advances to $300 \mathrm{~m}$, the far-field key strata break initially, and the broken distance is $160 \mathrm{~m}$, which is twice as large as that of the near-field key strata, which is shown in Figure 7(b).

\subsubsection{The Relationship between Advancement Distance with} the Height of Fracture Evolution. The evolution height of mining fractures in the overlying strata during the advance of the working face is statistically obtained, which is shown in Figure 8. The height of mining fractures develops to $90 \mathrm{~m}$, when the initial break of the near-field key strata occurs, and the advanced distance of working face is $160 \mathrm{~m}$. The fractures continue to develop upward, as the working face advances. When the working face advanced to $260 \mathrm{~m}$, the fractures develop to $123 \mathrm{~m}$ and remain stable, which is at the bottom of the far-field key strata. When the working face advanced to $320 \mathrm{~m}$, the fractures develop to the goaf of 14 \# coal seam. It is obvious that the fracture development can be prevented by the key strata to some extent; besides, the fractures develop to the goaf of $14 \#$ coal seam, when the far-field key strata break totally.

\subsubsection{Influence of Key Strata on the Overburden Fracture Evolution in Stope}

(1) Influence of Near-Field Key Strata on Fracture Surface Evolution. The near-field key strata were $61.2 \mathrm{~m}$ above the coal seams 3-5 \# and located in the fracture zone of "three zones." After the periodic fracture, a masonry beam structure was generally formed by the near-field key strata. When the separation zone of the upper part of the near-field key strata was large enough, all the soft rocks between the near-field key strata and the far-field key strata fractured and collapsed with the breakage of the near-field key strata. As a result, the fracture surface with a certain angle was formed at each rock layer.

(2) The Influence of Far-Field Key Strata on the Evolution of Fracture Surface. The far-field key strata were located $108.7 \mathrm{~m}$ above coal seams 3-5\#, and the distance between the key strata and the coal seam was 7.7 times of the mining thickness. When the coal seam was excavated to $240 \mathrm{~m}$, the far-field key stratum 1 was broken; when the panel was advanced to $300 \mathrm{~m}$, the far-field key stratum 2 was broken for the first time. At this time, the upper layer of the far-field key strata was deformed and broken, and the horizontal and vertical fractures were developed to the goaf of coal seam 14\#, forming the main fracture surface for water and gas conducting. The angle and height of fracture surface development are shown in Table 3. If the excavation was performed continuously, the fracture surface and the main fracture surface appeared alternately. The fracture distance of far-field key stratum 2 was about twice of that of near-field key strata.

According to the above analysis, the overburden key strata in stope play a controlling role in the evolution of the fracture surface. With the advance of the panel, the periodic mine pressure of the panel occurs, the overburden strata fracture periodically, and fracture surface appears 
TABLE 1: Simulated height of overburden.

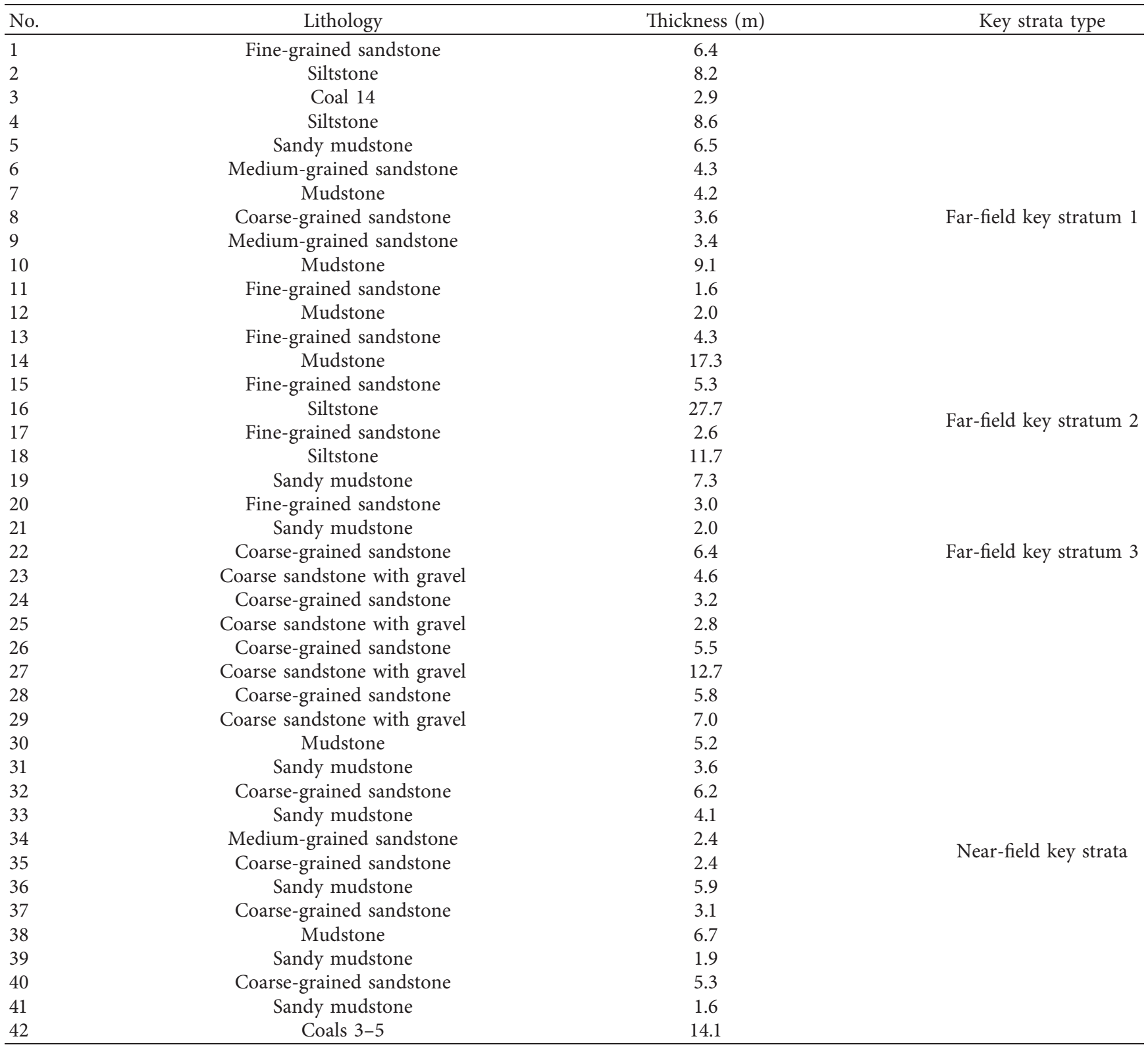

TABle 2: Physical and mechanical parameters of coal and rock layers.

\begin{tabular}{|c|c|c|c|c|c|c|c|}
\hline Lithology & $\begin{array}{c}\text { Thickness } \\
(\mathrm{m})\end{array}$ & $\begin{array}{c}\text { Burial depth } \\
(\mathrm{m})\end{array}$ & $\begin{array}{l}\text { Density } \\
\left(\mathrm{kg} / \mathrm{m}^{3}\right)\end{array}$ & $\begin{array}{c}\text { Tensile strength } \\
(\mathrm{MPa})\end{array}$ & $\begin{array}{c}\text { Compressive } \\
\text { strength }(\mathrm{MPa})\end{array}$ & $\begin{array}{c}\text { Elastic modulus } \\
(\mathrm{GPa})\end{array}$ & Poisson ratio \\
\hline $\begin{array}{l}\text { Fine-grained } \\
\text { sandstone }\end{array}$ & 6.44 & 346.13 & 2700 & 6.4 & 175.01 & 44.65 & 0.124 \\
\hline Siltstone & 8.21 & 354.34 & 2604 & 4.89 & 151.49 & 37.29 & 0.164 \\
\hline Sandy mudstone & 6.48 & 372.29 & 2681 & 4.4 & 143.98 & 38.07 & 0.291 \\
\hline $\begin{array}{l}\text { Medium-grained } \\
\text { sandstone }\end{array}$ & 4.3 & 376.59 & 2654 & 5.72 & 161.96 & 38.9 & 0.221 \\
\hline Mudstone & 4.2 & 380.79 & 2752 & 2.72 & 116.01 & 29.4 & 0.326 \\
\hline $\begin{array}{l}\text { Coarse-grained } \\
\text { sandstone }\end{array}$ & 3.64 & 384.43 & 2540 & 2.56 & 61.76 & 18.28 & 0.219 \\
\hline $\begin{array}{l}\text { Coarse sandstone } \\
\text { with gravel }\end{array}$ & 4.57 & 492.61 & 2528 & 3.2 & 54.75 & 15.33 & 0.232 \\
\hline Coal seams $3-5 \#$ & 14.05 & 592.18 & 1426 & 4.2 & 24.8 & 4.2 & 0.32 \\
\hline
\end{tabular}




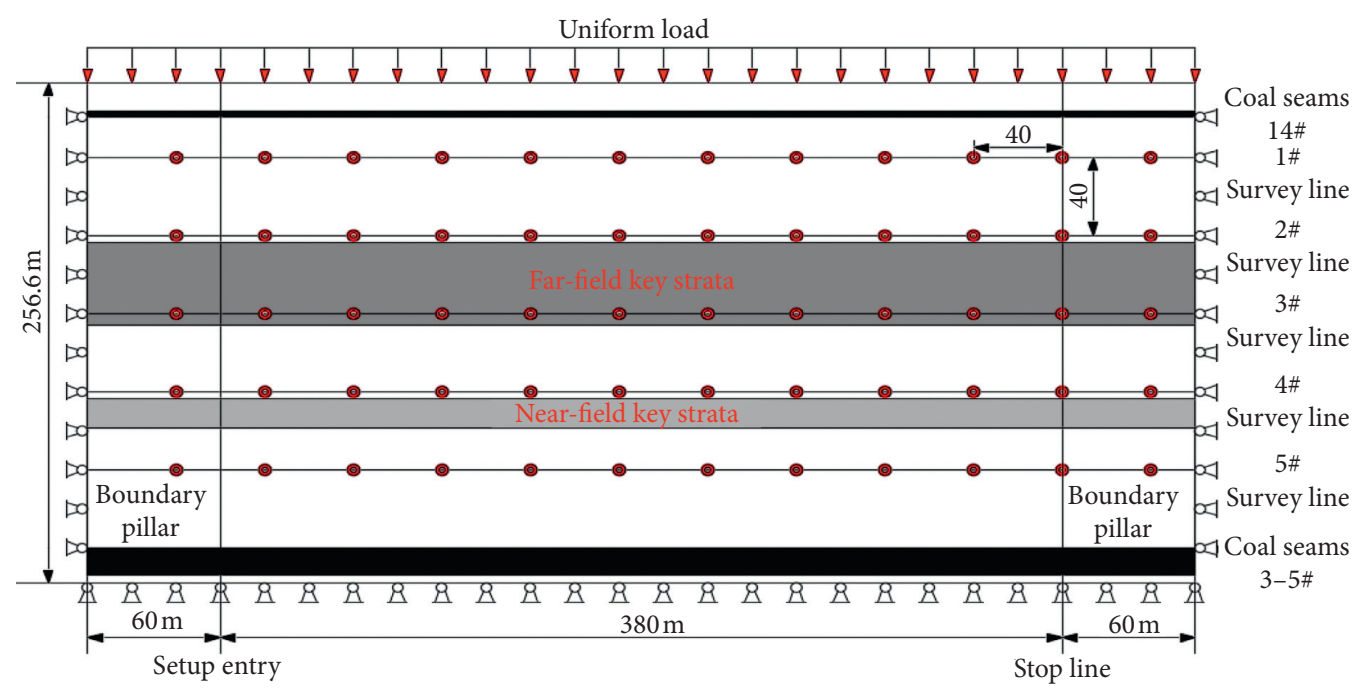

FIgURE 4: Layout and excavation diagram of model displacement measuring points.

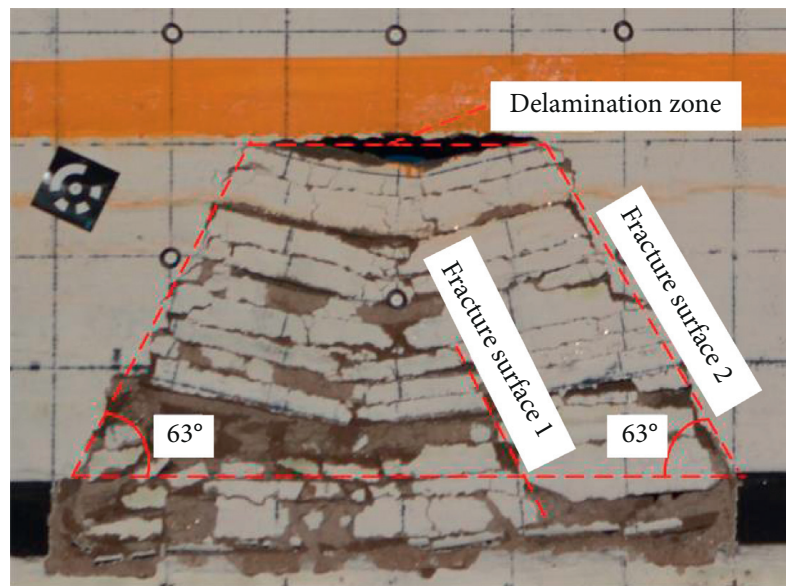

(a)

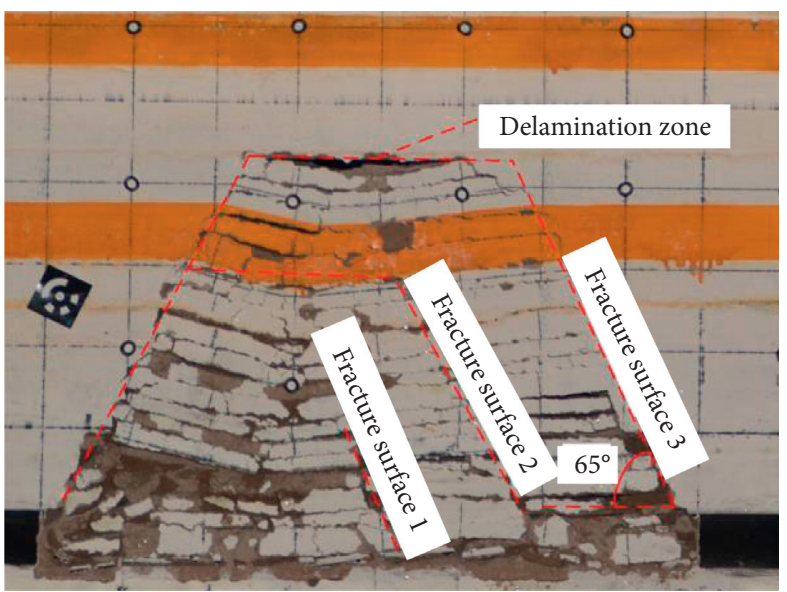

(b)

Figure 5: Movement and fracture evolution of overburden along with the panel: (a) the excavation of $120 \mathrm{~m}$; (b) the excavation of $160 \mathrm{~m}$.

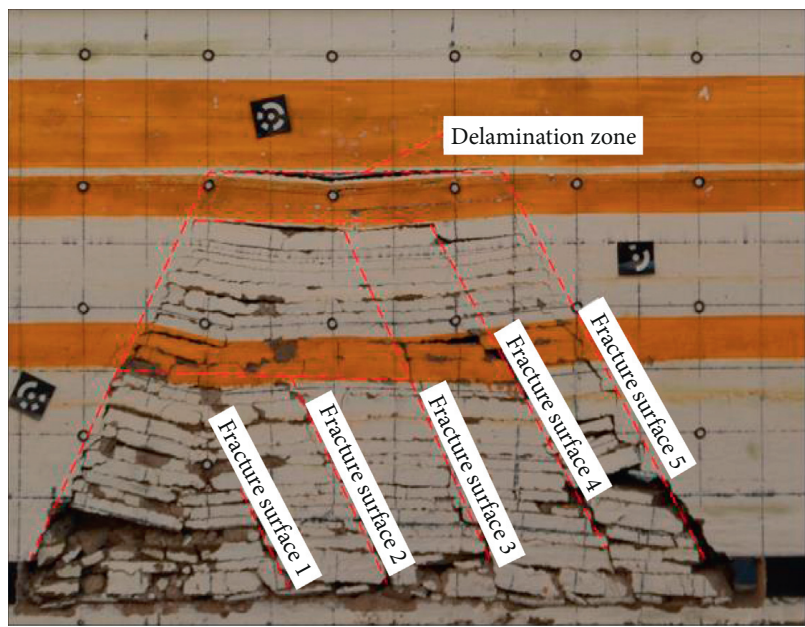

(a)

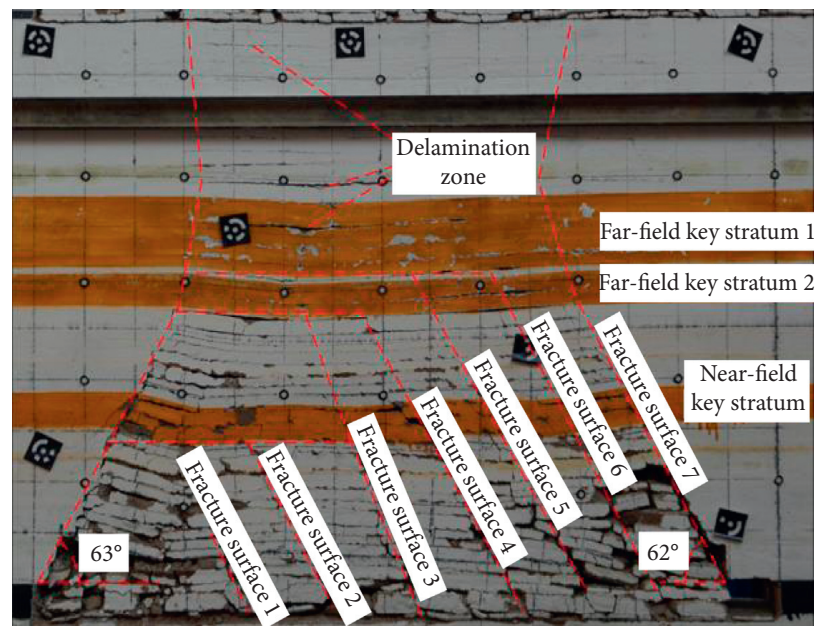

(b)

FIGURE 6: Movement and fracture evolution of overburden along with panel: (a) the excavation of $240 \mathrm{~m}$; (b) the excavation of $300 \mathrm{~m}$. 

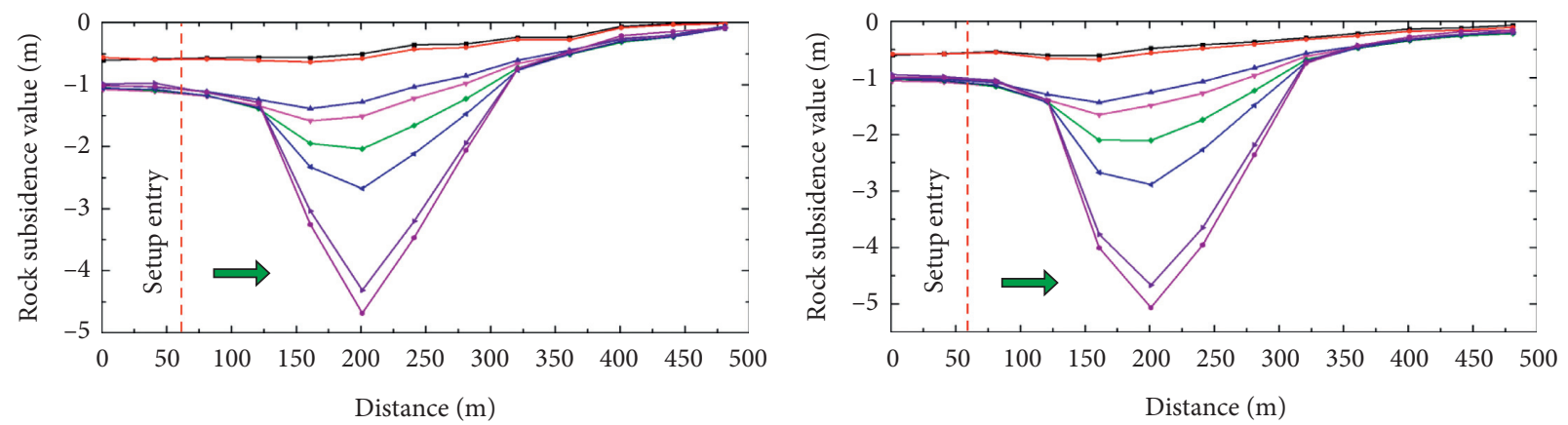

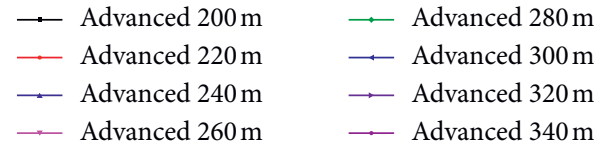

(a)

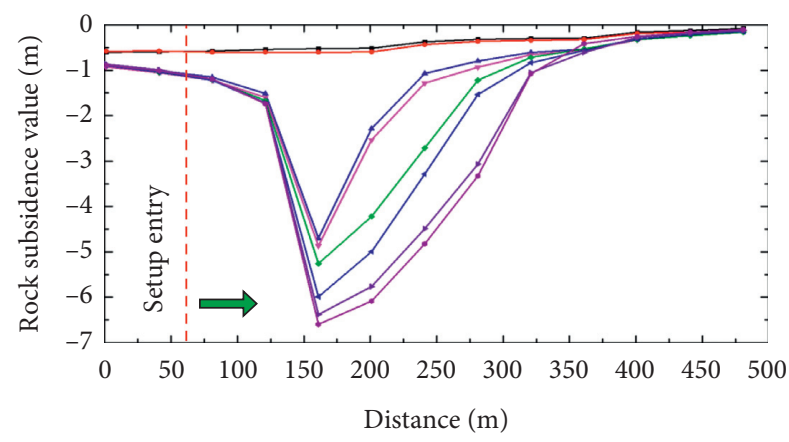

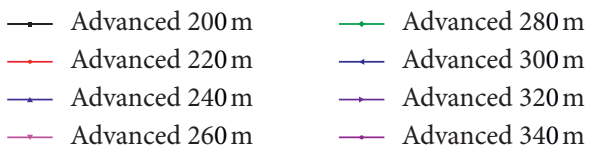

(b)

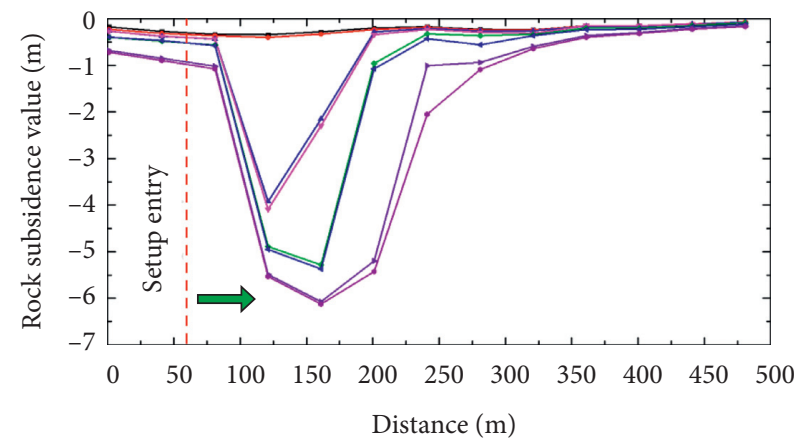

(c)

\begin{abstract}
- Advanced $280 \mathrm{~m}$
—_ Advanced $300 \mathrm{~m}$

$\rightarrow$ Advanced $320 \mathrm{~m}$

—_ Advanced $340 \mathrm{~m}$
\end{abstract}

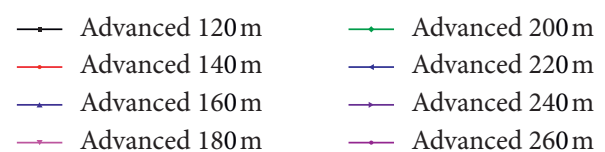

(d)
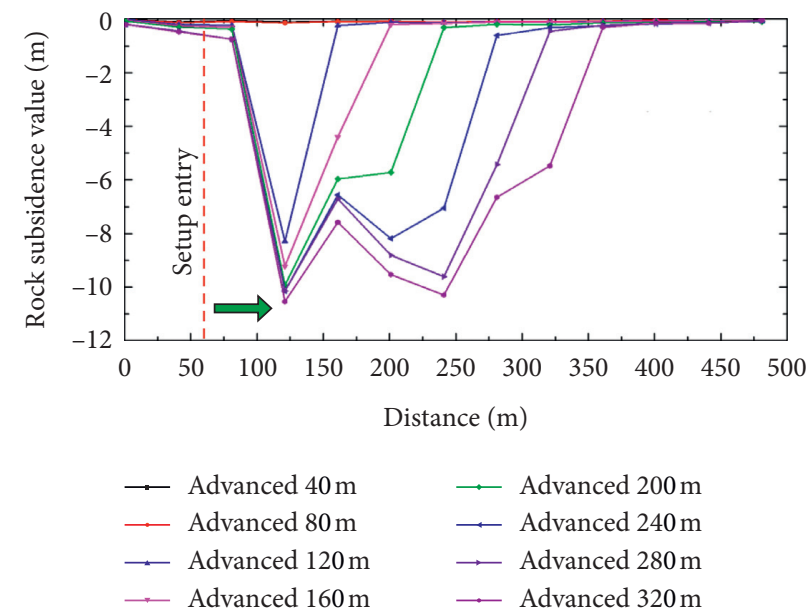

(e)

Figure 7: The vertical displacement curves of five survey lines: (a) the vertical displacement curve of survey line of number 1; (b) the vertical displacement curve of survey line of number 2; (c) the vertical displacement curve of survey line of number 3; (d) the vertical displacement curve of survey line of number 4 ; (e) the vertical displacement curve of survey line of number 5 . 


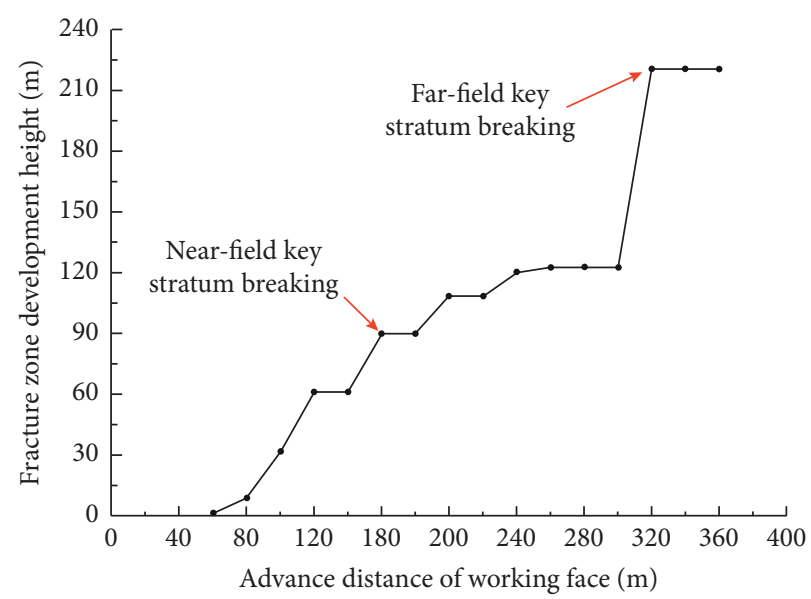

FIgURE 8: The relationship between advancement distance and the fracture evolution height.

TABLE 3: Relationship between advancement detail and the overburden fracture surface.

\begin{tabular}{lccc}
\hline Fracture type & Advancement $(\mathrm{m})$ & Height $(\mathrm{m})$ & Angle $\left(^{\circ}\right)$ \\
\hline Fracture surface 1 & 100 & 26.9 & 63 \\
Fracture surface 2 & 120 & 61.2 & 62 \\
Fracture surface 3 & 160 & 108.7 & 67 \\
Fracture surface 4 & 200 & 108.7 & 61 \\
Fracture surface 5 & 240 & 123 & 61 \\
Fracture surface 6 & 260 & 123 & 62 \\
Main fracture surface 7 & 300 & 220.9 & 62 \\
Fracture surface 8 & 320 & 123 & 62 \\
Main fracture surface 9 & 360 & 220.9 & 67 \\
\hline
\end{tabular}

periodically. Besides, the location of overburden failure and the height of the fracture surface increase, and the angle of the fracture surface is between $61^{\circ}-67^{\circ}$. The near-field key strata control the shape of the fracture surface of the lower strata, and the far-field key strata control the shape of the fracture surface of the lower strata and determine whether the fracture surface can be connected with the goaf.

4.2.5. Analysis of Water and Gas Discharge Process. When the far-field key strata were broken, the main fracture surface was formed. The water in the old goaf comes from rainfall, rivers, and the overlying aquifer, while the harmful gas in the old goaf come from the left coal spontaneous combustion. The water and harmful gas in the goaf of coal seam 14\# first diffused to the fracture in the upper layer of the far-field key strata and then entered the lower layer through the fracture surface of the far-field key strata structure. The water discharge is driven by gravity in the old goaf, while the discharge of harmful gas is controlled by negative pressure ventilation. Because the main fracture surface had a large opening fracture, the fracture surface behind the panel was closed with the advance of the panel, and most of the water and harmful gas were discharged from the main fracture surface to the goaf, as shown in Figure 9. The water discharge occurred at first, followed by the discharge of harmful gas in the old goaf. If there was a large amount of old goaf water and harmful gas, water inrush of the panel and harmful gas overrun can be caused. If the far-field key strata were thick or far away from coal seams 3-5\#, the far-field key strata did not break under the influence of mining but acted as the waterresisting key strata. As a result, the main fracture surface cannot be formed, and the old goaf water and harmful gas cannot be discharged.

\section{Analysis of the Relationship between the Water Level of Borehole and the Mine Pressure}

The fracture evolution of overburden is the result of the overburden movement during coal mining. The support rock pressure data can well reflect the collapse and fracture of overburden and obtain the periodic fracture distance of key strata. Therefore, during the observation of borehole water level, the mine pressure of 58\# support in the middle of the panel was observed, and the corresponding relationship between the water level and the maximum daily mine pressure of 58\# support was obtained, as shown in Figure 10.

As shown in Figure 10, three times of large mine pressures occur in the panel. When the panel was $188.3 \mathrm{~m}$ away from the borehole, the first mine pressure occurred; $114.6 \mathrm{~m}$ away from the borehole, the second mine pressure occurred; and $13.5 \mathrm{~m}$ away from the borehole, the third mine pressure occurred. When the third mine pressure occurred, the far-field key strata fractured periodically and 


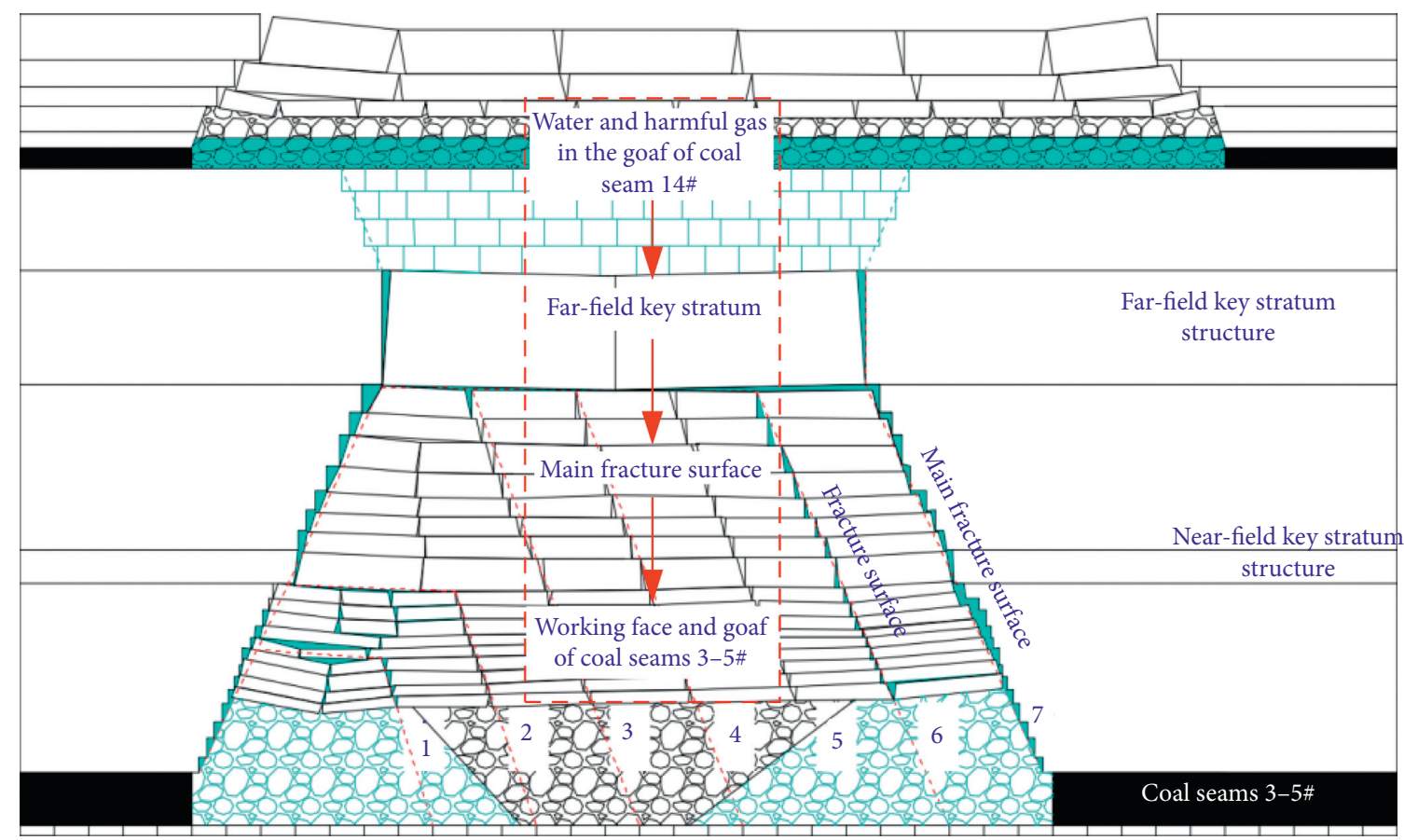

FIGURE 9: Schematic diagram of the water and gas drainage channel and process in the goaf.

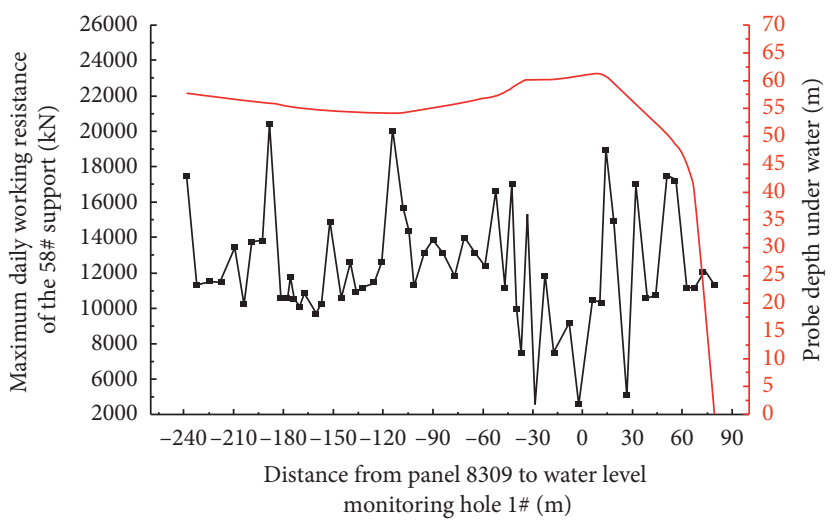

FIGURE 10: Relationship between water level of the borehole measuring point and mine pressure.

rotated gradually, and the borehole water level began to drop. Due to a small rotation angle of the far-field key strata in the early stage, the water level dropped slowly; in the later stage, the main fracture surface was formed, and the drilling water quickly dropped below the probe through the main fracture surface. The water level decreased from $0.62 \mathrm{~m} / \mathrm{d}$ to $0 \mathrm{~m} / \mathrm{d}$ during the advancement of the panel from $78.9 \mathrm{~m}$ to $85.9 \mathrm{~m}$. The angle range of the main fracture surface was calculated as $63.7^{\circ}-65.6^{\circ}$, which was consistent with the angle $62^{\circ}-67^{\circ}$ of the main fracture surface obtained by similar simulation. Therefore, the feasibility of the similar simulation is proved.

\section{Conclusions}

(1) The lithology of overburden and the key strata of farfield and near-field in the 8309 double-system extrathick seam of Tongxin coal mine are analyzed. It is concluded that there are a near-field key stratum and two far-field key strata above the 3-5\# coal seams. Besides, the similar simulation experiment is performed. The results show that a fracture surface with a certain angle can be formed by the periodic fracture of the far- and near-field key strata, and the fracture surface range is $61^{\circ}-67^{\circ}$.

(2) Based on the experimental analysis, the main fracture surface is formed by the fracture of the far-field key strata. The overall shape is "inverted trapezoid" in the upper part and "positive trapezoid" in the lower part, which is the necessary channel for the old goaf water and harmful gas discharge. If the far-field key strata do not break, an extrathick barrier layer can be formed. The fracture surface can only develop 
to the bottom of the far-field key strata, and there will be no water and gas discharge in the goaf.

(3) Through the observation of water level and mine pressure in the panel, the water level begins to drop after the panel is advanced to $13.5 \mathrm{~m}$ through the borehole, and the far-field key strata are completely fractured. When the key strata are broken and the development height of fractures reaches the maximum, the fracture surface is formed as the "main fracture surface," which is the only downward discharge pathway for goaf water and harmful gas. It is verified that under this condition, there is microfracture conduction between the panel and the overburden goaf.

\section{Data Availability}

The data used to support the findings of this study are included within the article.

\section{Conflicts of Interest}

The authors declare that they have no conflicts of interest.

\section{Acknowledgments}

This work was supported by the National Natural Science Foundation of China (U1904128, 51774110, 51704095, and 52004082) and Program for Science \& Technology Innovation Talents in Universities of Henan Province (19HASTIT047).

\section{References}

[1] H. W. Zhou, H. P. Xie, and J. P. Zuo, "Development in researches on mechanical behaviors of rocks under the condition of high ground pressure in the depths," Advances in Mechanics, vol. 1, pp. 91-99, 2005.

[2] D. Ma, H. Duan, W. Liu, X. Ma, and M. Tao, "Water-sediment two-phase flow inrush hazard in rock fractures of overburden strata during coal mining," Mine Water and the Environment, vol. 39, no. 2, pp. 308-319, 2020.

[3] X. X. Miao, H. Pu, and H. B. Bai, "Principle of water-resisting key strata and its application in water-preserved mining," Journal of China University of mining and technology, vol. 1, pp. 1-4, 2008.

[4] Z. Z. Cao, P. Xu, Z. H. Li, M. X. Zhang, Y. Zhao, and W. L. Shen, "Joint bearing mechanism of coal pillar and backfilling body in roadway backfilling mining technology," CMC-Computers Materials \& Continua, vol. 54, no. 2, pp. 137-159, 2018.

[5] D. Ma, J. J. Wang, and Z. H. Li, "Effect of particle erosion on mining-induced water inrush hazard of karst collapse pillar," Environmental Science and Pollution Research, vol. 26, pp. 19719-19728, 2019.

[6] Y. Xue, T. Teng, F. N. Dang, Z. Ma, S. Wang, and H. Xue, "Productivity analysis of fractured wells in reservoir of hydrogen and carbon based on dual-porosity medium model," International Journal of Hydrogen Energy, vol. 45, no. 39, pp. 20240-20249, 2019.

[7] W.-L. Shen, J.-B. Bai, W.-F. Li, and X.-Y. Wang, "Prediction of relative displacement for entry roof with weak plane under the effect of mining abutment stress," Tunnelling and Underground Space Technology, vol. 71, pp. 309-317, 2018.

[8] J. Liu, X. Liang, Y. Xue, K. Yao, and Y. Fu, "Numerical evaluation on multiphase flow and heat transfer during thermal stimulation enhanced shale gas recovery," Applied Thermal Engineering, vol. 178, Article ID 115554, 2020.

[9] D. Ma, H. Duan, X. Li, Z. Li, Z. Zhou, and T. Li, "Effects of seepage-induced erosion on nonlinear hydraulic properties of broken red sandstones," Tunnelling and Underground Space Technology, vol. 91, Article ID 102993, 2019.

[10] S. G. Li, C. S. Li, H. F. Lin, and L. H. Cheng, "Technique of drawing relieved methane and simultaneous extraction of coal and coakbed methane," Journal of Xi'an University of Science and Technology, vol. 263, pp. 247-249, 2002.

[11] Y. P. Cheng, J. H. Fu, and Q. X. Fu, "Development of gas extraction technology in coal mines of China," Journal of Mining and Safety Engineering, vol. 23, pp. 127-139, 2009.

[12] M. G. Qian and J. L. Xu, "Study on the "O shape" circle distribution characteristics of mining induced fracture in the overburden strata," Journal of China Coal Industry, vol. 5, pp. 20-23, 1998.

[13] J. L. Xu, X. Z. Wang, W. T. Liu, and Z. G. Wang, "Effects of primary key stratum location on the height of water flowing fracture zone," Chinese Journal of Rock Mechanics and Engineering, vol. 28, pp. 380-385, 2009.

[14] J. L. Xu, W. B. Zhu, and X. Z. Wang, "New method to predict the height of fractured water-conducting zone by location of key strata," Journal of China Coal Society, vol. 37, no. 5, pp. 762-769, 2012.

[15] J. L. Xu and J. F. Ju, "New method to predict the height of fractured water-conducting zone by location of key strata," Journal of China Coal Society, vol. 30, pp. 1547-1556, 2011.

[16] J. L. Xu and M. G. Qian, "Method to distinguish key strata in overburden," Journal of China University of Mining and Technology, vol. 29, no. 5, pp. 463-467, 2000.

[17] B. Yu, W. B. Zhu, R. Rui, and J. R. Liu, "Strata structure and its effect mechanism of large space stope for fully-mechanized sublevel caving mining of extremely thick coal seam," Journal of China Coal Society, vol. 41, pp. 571-580, 2016.

[18] B. Yu, W. B. Zhu, Z. Li, R. Gao, and J. R. Liu, "Mechanism of the instability of strata structure in far field for super-thick coal seam mining," Journal of China Coal Society, vol. 43, no. 9, pp. 2398-2407, 2018.

[19] W. B. Zhu and B. Yu, "Breakage form and its effect on strata behavior of far field key stratum in large space stope," Coal Science and Technology, vol. 46, pp. 99-104, 2018.

[20] S. G. Li, H. F. Lin, P. X. Zhao, P. Xiao, and H. Y. Pan, "Dynamic evolution of mining fissure elliptic paraboloid zone and extraction coal and gas," Coal Science and Technology, vol. 39, no. 8, pp. 1455-1462, 2014.

[21] X. Z. Wang, J. L. Xu, and W. B. Zhu, "Influence of primary key stratum structure stability on evolution of water flowing fracture," Journal of China Coal Society, vol. 37, no. 4, pp. 606-612, 2012.

[22] H. F. Lin, S. G. Li, L. H. Cheng, and H. S. Wang, "Experimental analysis of dynamic evolution model of mining-induced fissure zone in overburden strata," Journal of Mining and Safety Engineering, vol. 28, no. 2, pp. 298-303, 2011.

[23] D. Ma, H. Duan, Q. Zhang et al., "A numerical gas fracturing model of coupled thermal, flowing and mechanical effects," Computers, Materials \& Continua, vol. 65, no. 3, pp. 21232141, 2020.

[24] Y. Xue, P. G. Ranjith, F. N. Dang et al., "Analysis of deformation, permeability and energy evolution characteristics of 
coal mass around borehole after excavation," Natural Resources Research, vol. 29, pp. 3159-3177, 2020.

[25] D. Ma, J. Wang, X. Cai et al., "Effects of height/diameter ratio on failure and damage properties of granite under coupled bending and splitting deformation," Engineering Fracture Mechanics, vol. 220, Article ID 106640, 2019.

[26] S. G. Li, P. Y. Xu, P. X. Zhao, H. F. Lin, and H. Y. Pan, "Analysis and application on the mining height effect of evolving law of compaction area at fully mechanized face," Journal of China Coal Society, vol. 43, pp. 112-120, 2018.

[27] Q. X. Huang and H. M. Hu, "Experimental study on the whole process similar simulation material and proportion of stress and strain of clay aquiclude," Journal of Mining and Safety Engineering, vol. 34, pp. 1174-1178, 2017.

[28] K. Wang, S. C. Li, Q. S. Zhang et al., "Development and application of new similar materials of surrounding rock for a fluid-solid coupling model test," Rock and Soil Mechanics, vol. 37, pp. 2521-2533, 2016.

[29] D. Ma, M. Rezania, H.-S. Yu, and H.-B. Bai, "Variations of hydraulic properties of granular sandstones during water inrush: effect of small particle migration," Engineering $\mathrm{Ge}$ ology, vol. 217, pp. 61-70, 2017.

[30] J. T. Chen, L. M. Yi, W. B. Sun, C. Lu, S. C. Zhang, and X. Z. Sun, "Development and application of new deep solidfluid coupling similar materials," Chinese Journal of Rock Mechanics and Engineering, vol. 34, pp. 3956-3964, 2015.

[31] S. C. Li, X. D. Feng, S. C. Li, L. P. Li, and G. Y. Li, "Research and development of a new similar material for solid-fluid coupling and its application," Chinese Journal of Rock Mechanics and Engineering, vol. 29, no. 2, pp. 281-288, 2010.

[32] S. C. Li, Y. Zhou, L. P. Li et al., "Development and application of a new similar material for underground engineering fluidsolid coupling model test," Chinese Journal of Rock Mechanics and Engineering, vol. 31, no. 6, pp. 1128-1137, 2012. 